\title{
ROMANO GUARDINI: SACERDOTE, FILÓSOFO Y TEÓLOGO. UNA APROXIMACIÓN A SU PENSAMIENTO
}

Julio Cesar Zegarra Valdivia

Universidad Ricardo Palma

\section{RESUMEN}

La vida de Romano Guardini pasa por todas las interrogantes que un joven de 19 años puede tener. Llega incluso a distanciarse de su compromiso cristiano, de su fe cristiana, pero esto le servirá para asumir un compromiso mayor, el ser un sacerdote en Cristo y para Cristo por medio del servicio a sus hermanos los hombres. Le permitirá además ver y comprender la necesidad trabajar llevando el mensaje a todos mediante sus distintas obras a pesar de su precaria salud.

\section{PALABRAS CLAVE}

Alejamiento del cristianismo, compromiso cristiano, seguimiento a Cristo, Cristo centro de la vida cristiana, fe.

\begin{abstract}
The life of Romano Guardini faces all the main questions of a young man of nineteenth year old. He olso give up his christian compromis, and his christian faith but all of that was usefull for a bigger compromise, who is to became a priest in Christ and for Christ, throughout a life of service to his human brothers. That compromise help him to understand the necesity of work in given a message to all people by means of diverse actions despite a weak health.
\end{abstract}

\section{KEY WORDS}

Staying away from Christianism Christian compromise - following ChristChrist center of christian life-Faith. 


\section{DATOS DE SU VIDA Y ENCUENTROS DECISIVOS}

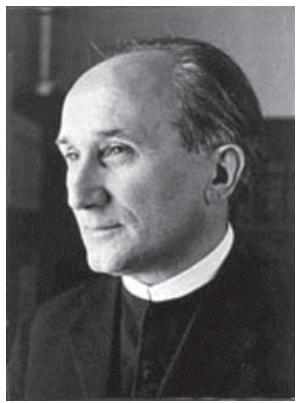

ROMANO GUARDINI

Romano Guardini nació el 17 de febrero de 1885 en Verona (Italia). Un año después la familia se traslada a Maguncia, donde también en 1903 aprueba el bachillerato. En el semestre de invierno de 1903/04 comienza en Tubinga la carrera de química. En el semestre de 1904/05, traslada su residencia de Tubinga a Múnich y cambia asimismo el estudio de la química por el de la economía política. Nuevamente un año después se marcha a Berlín, donde prosigue la carrera de economía política. Alfonso López Quintas nos dice: "En 1904, Guardini se vio alejado a sus 19 años de la fe cristiana, en parte debido a una desorientación intelectual. Durante las vacaciones converso ampliamente con un joven amigo, Karl Neundörfer, clarividente en cuestiones del espíritu y se entregó a lecturas selectas" (López, 2009, pp. 219 - 244). Es la lectura de la Biblia la que la va a dar las luces necesarias: una frase del Evangelio le permitió adivinar la energía y riqueza que alienta la buena nueva "Quien quiera salvar su vida la perderá; quien la dé la salvará” (Mt. 10, 39). Pero ¿darla a quién? Se preguntó Guardini. No a Dios directamente -se respondió a sí mismo-, "pues cuando el hombre pretende arreglárselas solo con Dios, dice 'Dios' y está pensando en él mismo". Esta experiencia marcará su vida y lo llevará por derroteros impensados. También le dará la posibilidad de comprender a los que buscan la fe como él también la buscó.

«Tiene que haber una instancia objetiva -agrega- que pueda sacar mi respuesta de los recovecos de mi autoafirmación. Pero sólo existe una instancia así: la Iglesia Católica, con su autoridad y precisión. Entonces sentí como si todo -realmente 'todo' mi ser- estuviese en mis manos, como en una balanza en equilibrio: 'Puedo inclinarla hacia la derecha o hacia la izquierda. Puedo dar mi alma o conservarla...' Y la hice inclinarse hacia la derecha. El momento fue completamente silencioso; no consistió ni en una sacudida ni en una iluminación, ni en ningún tipo de experiencia extraordinaria. Fue simplemente que llegué a una convicción: 'Es así, [...] ¡así debe ser!"(Guardini, 1992, pp. 99-100). Se descubre así mismo en Dios y para Dios. "Señor nos hiciste para ti y nuestro corazón está inquieto hasta que descanse en ti”(San Agustín, p. 256) 
Esta reflexión lo lleva a tomar la decisión de dar un nuevo giro a sus estudios. En el semestre de verano de 1906 se traslada a Friburgo de Brisgovia y empieza la carrera de teología. En el semestre de invierno de 1906/07 se produce un nuevo traslado de residencia de Friburgo a Tubinga continúa la carrera de teología. En octubre de 1908 ingresa Guardini en el Seminario Conciliar de Maguncia. Recibe las órdenes sacerdotales en la catedral de Maguncia el 28 de mayo de 1910. "Así para muchos personas de cierta edad, Romano Guardini - Sacerdote italiano incardinado en Alemania - fue un maestro de vida espiritual. Les hizo ver la jugosidad y profundidad de la acción litúrgica, les hizo familiar la grandeza de la figura de Jesús..." (López, p. XVII). Supo entregar el mensaje de Cristo, llevar la Buena Nueva desde su propia experiencia de vida.

A partir del año 1912 obtiene Guardini una beca para ampliación de estudios en Friburgo, que concluye en 1915 con una tesis doctoral. En Friburgo conoce Guardini a Joseph Frings, que luego llegaría a ser arzobispo y cardenal de Colonia; tuvo como compañero de estudios a Martin Heidegger. En el mismo año acepta Guardini la dirección de la Juventus, que le trajo contactos decisivos y posiciones orientadas al espíritu del movimiento juvenil, se convertirá en el lugar propicio para exponer su visión de la pedagogía. En el semestre de verano de 1922 comienza Guardini su carrera académica como docente privado de Dogmática en Bonn. Y en Bonn se le hace un primer ofrecimiento de la cátedra de teología práctica y ciencia de la liturgia. Guardini lo rehúsa. Se pone además en contacto con el llamado círculo de Scheler. En estos tiempos densos y movidos fue llamado en 1923 por la Universidad de Berlín para ocupar la cátedra de Filosofía de la Religión y Visión Católica del Mundo, creada expresamente para Guardini. Los nacionalsocialistas suprimieron esta cátedra en 1939, y Guardini pasó voluntariamente a la jubilación. En 1945 se le llamó para ocupar en Tubinga la cátedra de Visión Cristiana del Mundo. En el mismo año se suceden dos nuevos ofrecimientos para Múnich y Gotinga; y un tercero desde Friburgo para ocupar la cátedra de Martin Heidegger. Guardini los rechazó todos. En 1948 recibe un ofrecimiento para Múnich, y como ya antes en Berlín y Tubinga, con el fin de ocupar una cátedra ad personam. Guardini aceptó la oferta. En 1962 obtuvo el rango de emérito en Múnich.

El papa Pablo VI le ofreció la dignidad cardenalicia. Invitación que rehusó, aduciendo que esa dignidad no era para él, al parecer tenía muy en claro cuál era su misión. Lo que para el hombre Guardini fue decisivo, completamente esencial y -a pesar del acento académico de su vida- fue 
su actividad pedagógica y de cura de almas. Y él mismo escribe al respecto al considerar retrospectivamente su vida: «He considerado [al culto divino] tan estrechamente vinculado a la actividad en la Universidad, que cátedra y pulpito han sido uno en mi sentimiento; si se interpreta exactamente, ha sido una forma ideal del magisterio teológico» (Schreijäck, p. 4). Tras el Concilio Vaticano II, la atención de numerosos lectores, como es normal, se centró en otros autores y en otros temas, pero el pensamiento de Romano Guardini está siempre presente. No se debe olvidar que muchos de los padres conciliares ya habían leído sus obras publicadas años atrás.

El primero de octubre de 1968 murió Romano Guardini en Múnich. Por sus trabajos y méritos recibió numerosos e importantes reconocimientos. Se publicaron varios escritos suyos autobiográficos y diversas monografías sobre su vida y su obra. Se observa una renovación del interés por su estilo de pensar existencial, su ethos de verdad, su fidelidad inquebrantable a un ideal de vida cristiana entendida con flexibilidad de espíritu pero sin la menor adulteración.

Esta vuelta a Guardini es debida en buena cuenta a la edición de sus Obras Completas, promovida por la Academia Católica de Baviera, entre las que figuran varias obras póstumas, como la Carta a un amigo teólogo, Pensamientos en la frontera de la vida y La existencia del cristianismo. Esta última, que incluye las últimas lecciones dadas por el profesor en la Universidad de Múnich, y El contraste, Ensayo de una filosofía de lo viviente - concreto. "Este viejo ensayo es una producción de su juventud. (López, 1998, p.11) Es la obra filosófica de la que parte toda su producción. Han sido publicadas recientemente por la Biblioteca de Autores Cristianos de Madrid (Guardini). Adjunto a continuación la relación de obras que he podido encontrar de nuestro autor, pero muchas de ellas ya están agotadas. (Furlotti, p. 12)

\section{OBRAS DE ROMANO GUARDINI EN ESPAÑOL}

1948 El mesianismo en el mito, la revelación y la política, Rialp, Madrid.

1955 Pascal o el drama de la conciencia cristiana, Emecé, Buenos Aires-

1957 Cartas del lago de Como, Dinor, San Sebastián.

1960 Verdad y orden. Homilías universitarias I, Guadarrama, Madrid. Verdad y orden. Homilías universitarias II, Guadarrama, Madrid. Verdad y orden. Homilias universitarias III, Guadarrama, Madrid. Verdad y orden. Homilías universitarias IV, Guadarrama, Madrid. 
1961 El ángel en la Divina Comedia del Dante, Emecé, Buenos Aires.

1962 Voluntad y verdad, Dinor, San Sebastián.

1963 La cuestión judia, Sur, Buenos Aires.

1964 Religión y revelación, Guadarrama, Madrid.

1965 La esencia del cristianismo, Cristiandad, Madrid.

Los sentidos y el conocimiento religioso, Cristiandad, Madrid.

Preocupación por el hombre, Cristiandad, Madrid.

1981 Obras de Romano Guardini (tres tomos), Cristiandad, Madrid.

1982 Cristianismo y sociedad, Sígueme, Salamanca.

1989 La realidad humana del Señor, Lumen, Buenos Aires.

1992 La imagen de Jesús en el Nuevo Testamento, Lumen, Buenos Aires. Vida de la fe, Lumen, Buenos Aires.

1993 Introducción a la vida de oración, Lumen, Buenos Aires.

1994 La aceptación de sí mismo. Las edades de la vida, Lumen, Buenos Aires.

Libertad, gracia y destino, Lumen, Buenos Aires.

Una ética para nuestro tiempo, Lumen, Buenos Aires.

1996 Cartas sobre autoformación, Lumen, Buenos Aires.

El fin de la modernidad. Quien sabe de Dios conoce al hombre, PPC, Madrid.

1997 La existencia del cristiano, B.A.C., Madrid.

La muerte de Sócrates, Emecé, Buenos Aires.

2000 Ética, B.A.C., Madrid.

El Señor, Lumen, Buenos Aires.

Mundo y persona, Encuentro, Madrid.

2005 El espíritu de la liturgia. El talante simbólico de la liturgia, Agape, Buenos Aires.

2007 La conversión de San Agustín, Ágape, Buenos Aires.

Con la aparición de la magna Ética (editada en un solo volumen), tenemos por fin en español la parte más significativa de la obra guardiniana. En este momento podemos leerla con nueva perspectiva debido a un mejor conocimiento de la personalidad del autor. Este solía hablar muy poco de sí mismo, debido a su innata timidez, pero nos legó un par de diarios que nos revelan ciertos aspectos de su intimidad (López, 1998, p.18). Por ejemplo se comenta de su capacidad para llegar a sus oyentes, tanto en homilías como en sus ponencias.

En sus actuaciones públicas, Guardini producía una impresión de seguridad y vitalidad. Su talante era siempre constructivo y su doctrina 
constituía una positiva afirmación de la vida en todos sus valores. El oyente tendía a pensar que se hallaba ante un triunfador sin temores, sin la menesterosidad de quienes tienen que ganar su equilibrio espiritual a través de mil dificultades. Sus escritos nos muestran un hombre de salud quebradiza, que afronta esforzadamente, hasta el límite de sus fuerzas, los grandes retos que le impuso su voluntad de servir a los demás en el plano pastoral e intelectual. Siempre fue consiente que su dignidad era para el servicio, no para servirse de ella.(Zegarra, pp. 83-91) Más de una vez pareció rendirse a la fatiga y sentir como una liberación el cesar en su actividad de conferenciante y escritor. Pero la conciencia de que lo más importante estaba todavía por hacer acrecentaba sus fuerzas y volvía al trabajo espiritual e intelectual.

Este mayor conocimiento de la fragilidad del admirado profesor nos acerca a su figura y la torna más entrañable, más humana. Ahora podemos leer entre líneas sus obras y entre ver el esfuerzo que implicó para él el clarificar la forma cristiana de ver el mundo y sus manifestaciones culturales.

Por eso todo podemos afirmar que su pensamiento se centra en el opúsculo. "Sólo el que ama a Dios conoce al hombre" (López, 1995). Es por eso que podemos afirmar con Guardini que en la medida que nos aproximemos a Dios, y que sobre todo participemos de él, nos acercamos a nuestra propia comprensión, y lograremos una mayor aceptación de nosotros mismos. Esto nos llevará a la comprensión y aceptación de los demás. "La sede del sentido de mi vida no está en mí, sino por encima de mí. Vivo de lo que está por encima de mí. En la medida que me encierro en mí o - lo que viene a ser lo mismo - me encierro en el mundo, me desvío de mi trayectoria" (Guardini, 1997, p. 180). Es por eso que podemos afirmar que el hombre que entra en contacto con Dios, que centra su existencia en Dios vive en un estado de paz consigo mismo. Entonces diremos con San Pablo “...Ya no soy yo quien vive en mí, sino es Cristo Jesús, Nuestro Señor quien vive en mí” (Ga. 2, 19-21) Una vida en Cristo Jesús totalmente identificada y plena capaz de ser transmitida.

Esta tención hacia lo alto, típica del talante melancólico que tanto sufrimiento deparó a Guardini a lo largo de su vida, otorga a sus obras un hálito de vida espiritual que tan aleccionadora resulta para quienes deseamos superar la cortedad de miras del espíritu mundano. A este respecto es importante la obra de Alfonso López Quintás. Alumno de Guardini que 
se preocupó por conseguir los permisos correspondientes para que las obras de su maestro puedan se traducidas y publicadas en castellano.

Tenemos tres razones sólidas para pensar que la vuelta actual a Guardini va a revertir especial intensidad por dos razones: Primero la tarea que abordó intensamente en su vida sigue siendo actual y urgente y Segundo el mejor conocimiento de su biografía nos ha hecho su figura más cercana y más aleccionadora todavía. Esta es la intención del Monseñor Alfonso López Quintás en su famosa obra: Romano Guardini, maestro de vida (López, 1998).

Un acercamiento al pensamiento de Romano Guardini

\section{LA ESENCIA DEL CRISTIANISMO}

Iniciamos este pequeño comentario tomando como base la advertencia preliminar que se encuentra en la obra editada por Ediciones Cristiandad:

“El presente ensayo se publicó en 1929 en la revista Die Schildgenossen. El número en que apareció está agotado desde hace ya largo tiempo. Por eso he creído, accediendo a numerosos ruegos, que merecía que se publicase nuevamente, más que nada por la relación que tiene con otros dos libros lanzados en la misma editorial: La imagen de Jesucristo en el Nuevo Testamento y El Señor. En él se expone, si así puede decirse, la categoría necesaria para la comprensión estos dos últimos y viene a ser como una introducción metódica a los mismos" (Guardini, 1965, p. 14). Esta advertencia nos muestra la sencillez y a la vez la importancia del pensamiento de nuestro autor. Es tal la profundad de su reflexiones que nos deja con ese deseo de continuar profundizando más y más. Nos va llevando de la mano y con el cariño de un padre espiritual que quiere compartir con nosotros su experiencia de vida en Cristo Nuestro Señor. Aquí la tesis esencial de su obra es que la Persona de Jesucristo, y no una doctrina, es el centro del cristianismo, por ser su existencia, su obra. "Ser cristiano es para él lo mismo que ser creyente e incluso que ser religioso" (Guardini, 1965, p. 15). El compromiso del cristiano debe ser tal que debe transparentar la presencia de Cristo en su vida en general, llámese: pensamiento, palabra y obra. En otras palabras, convertirnos en otros Cristos, nuevos hombre. Claro que esta presencia se inicia con el sacramento del bautismo. En realidad no pide nada nuevo, pero si nos lo recuerda con energía y claridad. "Porque 
por el bautismo nos configuramos con Cristo: Porque también todos nosotros hemos sido bautizados en un solo Espíritu para formar un solo cuerpo (1Cor.12, 13). Rito sagrado con que se presenta y efectúa la unión con la muerte y la resurrección de Cristo: Porque con él hemos sido sepultados por el bautismo, para participar en su muerte,...también igualmente lo seremos por la de su resurrección (Rom. 6, 4-5) Vemos con claridad que está presente el pensamiento del padre Guardini en el Concilio Vaticano II, quizá no explícitamente, pero está en la mente de los padres conciliares. Esto me recuerda lo sucedido con los libros de Moral del Padre Marciano Vidal, muchos hemos sido formados bajo sus postulados sobre moral cristiana. $\mathrm{Se}$ descubren algunos pequeños conflictos con las orientaciones de la Sagrada Congregación para la Doctrina de la $\mathrm{Fe}$, y no por eso debemos hacer "Borrón y cuenta nueva". Al contrario, estará presente su pensamiento nos ayudará para comprender mejor la visión antropológica desde la perspectiva cristiano-católica, tema que fue tratado en un anterior artículo en esta Revista de Aula y Ciencia. (Zegarra, p. 113) Somos por tanto miembros del cuerpo Místico de Cristo. Es verdad que cuando nos bautizamos, no podemos decir si aceptamos o no dicho sacramento, pero son nuestros padres quienes asumen por nosotros la respuesta, y la Iglesia nos concede el Sacramento en la Fe de nuestros padres y padrinos. Son responsabilidades que al parecer, en muchos casos ya sólo queda en el papel.

Podemos preguntar ahora al Nuevo Testamento si todo lo afirmado hasta el momento es cierto, y además cuál es la posición de la persona de Jesucristo dentro de la religión cristiana.

Basta con una mirada superficial para darnos cuenta de la inconmensurable significación que reviste la personalidad de Jesús en el Nuevo Testamento. Podemos empezar por el Sermón de la montaña, por ejemplo, se contrapone la frase "se dijo a los antiguos", a esta otra: "Yo empero os digo" (Mt. 5, 21-22). La conciencia de máxima autoridad que mencionamos líneas arriba, resuena en las palabras una y otra vez repetidas: "En verdad, en verdad os digo" (Mt. 7, 29). Subrayado por la admiración de sus oyentes, Jesús "enseñaba como quien tiene poder y no como los sabios y eruditos doctores que sólo repetían de memoria sin autoridad alguna, y muchas veces $\sin$ interiorizar lo que predicaban.

En su mensaje afirma el mismo Jesús: El cielo y la tierra pasarán, pero mis palabras no pasarán" (Mt. 24, 35). Hace referencia a la intemporalidad de sus palabras, ellas siempre permanecerán aunque las generaciones 
pacen. Todas las palabras habladas por Él “son espíritu y vida” (Jn. 6, 63), y dice más todavía: "y el que las escucha... y las pone en práctica será como el hombre prudente que edifica su casa sobre roca" (Mt. 7, 24), aunque llegue la tormenta no podrá con ella.

Así pues "Jesucristo anuncia un nuevo orden de las cosas, un mundo de realidades y fuerzas espirituales hasta entonces desconocidas, el "reinado de Dios..." (Guardini, 1965, p.25). En todo se revela pues, una autoridad máxima religiosa, autoridad que le concede el reconocerse como Hijo de Dios. "Jesús exige explícitamente que los hombres le sigan. Que le sigan no en el sentido de estar dispuestos a reconocer como ejemplar su figura de Maestro, sino en el sentido, mucho más profundo, de negarse a sí mismos" (Guardini, 1965, p. 25). En la Biblia tenemos varis pasajes donde claramente está presente e la exigencia de Jesús. “... El que no coge su cruz y me sigue no es digno de mí" (Mt. 10, 34ss), es pues, para su tiempo una exigencia y un compromiso hasta entonces poco común. Además recordemos que la cruz era signo de escarnio, de culpa, de castigo y no signo de vida. Es con Cristo que se traduce en signo de vida, de salvación y gloria.

De las frases citadas se deduce con toda claridad que la elección exigida no es sólo de naturaleza ética, es decir, que no se halla situada bajo la norma de lo bueno y de lo que implica salvación, sino que se dirige a la persona misma de Jesús y significa una decisión propia de amor, de entrega total. Pero debemos también tener en cuenta que Jesús no sólo exige, sino que también ama, y el llamamiento que dirige al hombre es de amor. "Se le quedó mirando y le tomo cariño", se lee en la historia del joven rico (Mc. 1021), de la misma manera que toda la existencia de Jesús surge de ese inmenso amor de Dios hacia el hombre caído por el pecado, la humanidad caída. "Porque así demostró Dios su amor al mundo, entregándonos a su Hijo único y amado". (Jn. 3, 16). Es por eso que frente a este inmenso amor debe corresponder también de nuestra parte una respuesta de amor y compromiso con Dios y con él prójimo. Así dice El mismo: "Si me amáis guardareis mis mandamientos...” (Jn. 14,15).

Todavía más enérgicamente se expresa Jesús en las palabras cuando instruye a los Apóstoles: "El que os recibe a vosotros, me recibe a mí, y el que me recibe a mí, recibe al que me ha enviado" (Mt. 10, 40). "Quien os escucha a vosotros me escucha a mí, y quien me rechaza a mí, rechaza al que me ha enviado..." (Lc. 10, 16). Así pues, es Jesús mismo quien vive en cada uno de sus discípulos. Por tal motivo tanto el comportamiento justo o injusto que tengan con sus discípulos, es con él o en contra de él. 
Jesús es pues, el núcleo, la justificación y la fuerza de la nueva comunidad religiosa: "Os lo digo... donde estén dos o más reunidos en mi nombre,... allí en medio es ellos estaré yo" (Mt. 18, 19-20). Nos expresa constante mente que estará siempre junto a nosotros. En último término es y debe ser el centro de nuestra vida.

Hay un pasaje que debe llevarnos a reflexionar sobre nuestra conversión, sobre nuestro compromiso bautismal y todo lo que ello implica. "Juan le dijo: Maestro, hemos visto a uno que echaba demonios en tu nombre y hemos intentado impedírselo porque no anda con nosotros. Jesús respondió: no se lo impidáis, porque nadie que haga un milagro usando mi nombre puede a continuación hablar mal de mí” (Mc. 9, 38-39). Esto trae a mi memoria una de las frases del Papa Francisco I "Si ellos se arrepienten y buscan el perdón de sus pecados, quien soy yo para condenarlos". Valdría la pena que nos preguntásemos: estamos en la capacidad de juzgar y condenar al otro, estamos lo suficientemente libres de culpa como para mirar la paja en el ojo ajeno, podemos ya lanzar la primera piedra o todos tenemos algo por qué arrepentirnos, ya que esas faltas nos alejan de la presencia de Dios y hace que nos ocultemos ante su llamado por la vergüenza de nuestra vida de pecado.

San Pablo expresa el mismo significado: "Entre vosotros tened la misma actitud del Mesías: Él a pesar de su condición divina, no se aferró a su categoría de Dios; al contrario se despojó de su rango y tomó la condición de esclavo, haciéndose pasar por uno de tantos. Así, presentándose como simple hombre, se abajó, ofreciéndose hasta la muerte, y una muerte en cruz. Por eso Dios lo encumbró sobre todo y le concedió el título que sobre pasa todo título; de modo que a ese título de Jesús toda rodilla se doble en el cielo, en la tierra, en el abismo- y toda boca proclame que Jesús, el Mesías, es el Señor, para gloria de Dios Padre" (Flp. 2, 5-11). Se nos habla del desapego a los títulos, a las cosas materiales. Esto no indica que no se deban usar las cosas materiales, tampoco que sean malas; estas fueron creadas para usarlas, pero no están por encima del hombre, están al servicio del hombre y para el hombre.

Si revisamos el libro de los Profetas encontraremos que siempre inician sus relatos. "El señor dice...", "Yahvé dice...". A partir de aquí nos conduce pues, a las manifestaciones mesiánicas: "Yo soy el que soy...". Por ejemplo "Vosotros sois mis testigos - oráculo del Señor - y mis siervos, a quienes yo escogí, para que supierais y me creyerais, para 
que comprendierais quién soy yo,... Yo soy el Señor; fuera de mí no hay salvador. Yo predije y salvé; yo anuncié y no teníais dios extranjero. Vosotros sois mis testigos -oráculo del Señor"- (Isaías 43, 10-112). Vemos aquí "algo totalmente diverso de la actitud pedagógica del maestro que llevando una vida ejemplar, une el peso de su persona con la autoridad de la ley ética, a fin de que esta arraigue más en el corazón de sus discípulos..." (Guardini, 1965, p. 45) . Busca pues, preparar el camino y la llegada de su Hijo, sobre todo preparar el corazón de los hombres, para que reciban al Mesías.

Ahora bien, la decisión de seguir a Jesús implica un compromiso, un cambio total de vida. Él viene a cambiar todo a poner en conmoción las relaciones y las conexiones humanas naturales. Podemos ver esto claramente cuando nos dice: "No penséis que he venido a sembrar paz en la tierra; no he venido a sembrar la paz, sino espadas; porque he venido a enemistar al hombre con su padre, a la hija con su madre, a la nuera con la suegra: así que los enemigos de uno serán los de casa....El que quiera a su padre o a su madre más que a mí, no es digno de mí; el que no coge su cruz y me sigue, no es digno de mí. El que encuentre su vida la perderá, y el que pierda su vida por mí la encontrará" (Mt. 10, 34-39). Viene a cambiar las estructuras antiguas, sobre todo a cambiar los corazones de todos a aquellos que lo quieran seguir y que se quieran convertir en sus discípulos. Es un compromiso que implica rasgarse el corazón y no las vestiduras como acostumbraban los doctores de la ley. Es pues, la decisión por esencia. Es por eso que en otra cita bíblica nos dice: "El que no está conmigo está contra mí y el que no recoge conmigo desparrama” (Mt. 12, 30). Jesús no permite una decisión a medias, es o no es tu compromiso. Soy consciente de que esto escandaliza, pero justamente creo que se trata de eso, de que yo descubra que estoy en falta, en peligro de perder mi vida.

Otro rasgo importante en la pedagogía de Jesús es que se nos presenta como el "Camino", la "Verdad" y la "Vida". En ningún momento nos dice: yo vengo a enseñarles el camino, tampoco dice yo les traigo la verdad y, menos aún, yo les traigo la vida. Esa es una diferencia clara y marcada frente a cualquier otro líder religioso, ya sea de la época de Jesús o ahora en nuestro tiempo. "Nadie se acerca al Padre sino es por mi" (Jn. 14, 6-11). Es pues, Cristo quien nos revela al Padre. Sin Cristo no es posible el conocimiento del Padre. Por tanto es esencial su presencia, es un principio que no puede ser eliminado. Esta visión, claro está, se opone a la de algunos grupos religiosos que sólo toman a Jesús como un profeta mayor y no como 
Hijo de Dios, su bien amado. Así Jesús al hacerse hombre como nosotros y habitando entre nosotros, dejó abierto el camino para el encuentro con el Padre, nos conduce hasta el Padre. Ahora bien, una vida en Cristo y para Cristo nos conduce a una vida para Dios y con Dios. Es por eso que participar de la Eucaristía es participar de la vida de Cristo y con Cristo que a su vez es participar con él de la vida del Padre.

Bueno, creo que es suficientemente claro que Cristo es la esencia del cristianismo, no hemos revisado las cartas paulinas, porque hemos preferido ceñirnos sobre todo a los Evangelios. Sin embargo colocaremos esta cita: "En las cartas paulinas se encuentra continuamente, no dice Guardini, una expresión singular 'en Cristo'. Así por ejemplo, en las fórmulas de salutación, al principio y al final, como cuando la primera Epístola a los Corintios se dirige 'a la iglesia de Dios, de Corinto; y a los santificados en Cristo Jesús', terminando con la expresión: 'mi amor está con vosotros en Cristo Jesús" (Guardini, 1965, p. 71). Por todo lo dicho hasta aquí sobre San Pablo, creo que con justicia se le puede llamar "El fundador de la teología del Corazón de Jesús. En él se encuentran las ideas y las actitudes religiosas que podrían servir para superar los sentimentalismos que desfiguran la Idea del Corazón de Jesús" (Guardini, 1965, p. 75). Así pues, podemos afirmar con toda seguridad que el cristianismo es la religión del amor, pero no se habla de cualquier tipo de amor, sino de aquél amor que va dirigido a la persona de Jesús y en él es que se hace absoluto. Así pues, "La tesis de que el cristianismo es la religión del amor solo puede ser exacta en el sentido de que el cristianismo es la religión del amor a Cristo y, a través de Él, del amor dirigido a Dios, así como a los otros hombres (Guardini, 1965, p. 105).

\section{CONCLUSIÓN}

Esta es pues la Esencia del Cristianismo, centro alrededor del cual todo gira. Es a partir de aquí que debe nacer nuestro compromiso. Recordando siempre que con el bautismo hemos participado de la muerte de Cristo para resucitar a una vida eterna con El.

Nuestro autor nos muestra pues el camino netamente humano. Primero vemos un alejamiento del joven Guardini de la fe recibida de sus padres y de su formación temprana. Personalmente creo que es la parte más humana, y que puede sucedernos a cualquiera de nosotros, esa duda, ese no ver las cosas claras, así optamos por dejar de lado el problema y 
creemos que así se solucionó. Pero es el mismo Guardini quien nos dice que el problema está ahí a la espera de una solución. En el caso de nuestro autor este problema lo lleva a buscar los medios necesarios para enfrentar esta duda, esta falta de fe.

Serán justamente las Sagradas Escrituras las que le abrirán el sendero, la darán las luces para buscar a Dios en su interior. Tal como San Agustín dice "No salgas de ti, ya que en ti habita Dios", somos pues templos vivos del Espíritu Santo. Esto es lo que hace Guardini buscar dentro del él a Dios y descubre que es mediante el servicio a los hermanos, los cristos vivientes. Esto lo llevará por derroteros jamás pensados por él. Deja los estudios que está siguiendo y opta por la teología y el ingreso al seminario.

El reconoce que es un persona de salud frágil, pero toma distintos cargos, el más duro pero más gratificante fue el trabajo con los jóvenes, posteriormente asume la docencia en distintas Universidades. Pero esto jamás lo alejó del pulpito y sus predicaciones. Nuevamente conviene citar a San Agustín: "Señor dame lo que me pides y pídeme lo que quieras". Así Guardini encontraba en Dios la cura para el problema de la depresión y la melancolía que lo atormentaban constantemente. Es por eso que la mayoría de sus obras nos llevan a un encuentro con Dios, único remedio del alma, ahí radica su importancia.

\section{REFERENCIAS BIBLIOGRÁFICAS}

GUARDINI, Romano.

1965 La esencia del cristianismo. Madrid: Ediciones Cristiandad.

1992 Apuntes para una autobiografía. Madrid: Encuentro

1995 Quien sabe de Dios conoce al hombre. Madrid: PPC. Un estudio introductorio de Alfonso López Quintás

1997 La existencia del cristianismo. Madrid: Biblioteca de Autores Cristianos.

2000 Ética: lecciones en la Universidad de Múnich. Estudio introductorio por Alfonzo López Quintas. Madrid: Biblioteca de Autores Cristianos

LÓPEZ QUINTÁS, Alfonso

1998 Romano Guardini, maestro de vida. Madrid: Ediciones Palabra. 
LA SANTA BIBLIA

1964 Traducida de los textos originales en equipo bajo la dirección del Dr. Evaristo Martín Nieto $10^{\mathrm{a}}$ ed. Madrid: Ediciones Paulinas.

\section{SAN AGUSTÍN}

1957 Las confesiones. Madrid: Real Monasterio de El Escorial.

ZEGARRA VALDIVIA, Julio César

2010 Una aproximación al pensamiento de Marciano Vidal. En Aula y Ciencia. Lima: Universidad Ricardo Palma. Año III. N 4-5.

2009 La autoridad como servicio. En Aula y Ciencia. Lima: Universidad Ricardo Palma. Año III Nº 2.

DOCUMENTOS COMPLETOS DEL CONCILIO VATICANO II 1982 Bilbao: Ediciones Mensajero.

\section{RECUPERADOS DE INTERNET}

LÓPEZ QUINTAS, Alfonso.

2009 La antropología relacional-dialógica de Romano Guardini. Revista Veritas, Vol. IV, N²1 219 - 244. http://www.revistaveritas.cl/wpcontent/uploads/2009/09/01_Alfonso-Lopez-Quintas.pdf

SCHREIJÄCK, Thomas

S/F Bildung als Inexistenz. La obra filosófica de Romano Guardini. Salzburgo. http://www.mercaba.org/Guardini/la_obra filosófica de Romano.htm

FURLOTTI, Pablo

S/F La Persona Humana Reflexiones de en torno a la obra Mundo y Persona de Romano Guardini. Facultad de Derecho y Ciencias Sociales U.N.T. Centro de Estudios Paideia / Politeia Proyecto: República, Escuela y Democracia, pp. 12, 13. http://www.paideiapoliteia. org/AR. 